\title{
Research on Situation and Countermeasures of Employee E-learning Training in Chinese Enterprises
}

\author{
Wang Xin ${ }^{1, a}$, Qu Xiaoting ${ }^{2, b}$ \\ ${ }^{1,2}$ School of Economics and Management,Beijing Jiaotong University,Beijing,China \\ awangxinrose@126.com bxtqu@bjtu.edu.cn
}

Keywords: E-learning;training;countermeasures

\begin{abstract}
Under the new economic times,enterprises are confronted with increasingly fierce competition.How to use the most convenient and efficient way for employee training has become the key to the development of enterprise and become important research direction of enterprise training.Through the analysis of current situation for employee E-learning training,enterprises based on E-learning training make use of advantages of reducing costs, improving efficiency and so on.But at the same time,there are still some problems,for example,lack of targeted training curriculum and resources,the barrier for direct communication.So it is necessary to set up correct ideas of E-learning training, establish perfect personalized training certification system,evaluate training effect and take some other countermeasures.
\end{abstract}

\section{Introduction}

Corporate training and development agency recent studies have shown that E-learning occupies the first place in improving the performance of digital learning method, which is investment options of big enterprise.As a significant method of enterprise information,E-learning servicing for the enterprise training is also a complete set of knowledge management system.Through the analysis of the differences of each learner and direction,the study demand can be obtained.Enterprises incentive and monitor learners in a certain way to ensure the learning effect.Enterprises carry out E-learning project for two reasons generally including inside and outside aspects.From the internal factors,each enterprise face to the same problem, namely training is not in time, limited use of resources and coverage and so on.From the external factors, in the information technology and knowledge economy era, enterprises attach growing importance of human resources and new learning methods.How to make use of their own advantages and play their values have become a new topic for the training department.

\section{Summarization of E-learning}

\section{Implication of E-learning for enterprise training}

E-learning is a new way of learning based on the Internet platform by building digital resources.Learners connect the Internet via a PC or telephone to learn anywhere at any time ${ }^{11]}$.

E-learning for employee training means a new approach to learn and train mainly through the computer network of learning and teaching activities. It makes full use of modern information technology that provides learning environment with a new communication mechanism and rich resources.This cannot simply be equated with electronic training or remote education, but also contains the mutual communication and sharing of knowledge between employees, and includes the solutions to evaluation of learning experience and management.

\section{Basic characteristic of E-learning}

(1)Facilitation.Due to the interconnectedness of the Internet,E-learning has some advantages that are relative to Internet.At the same time, it enables learners to acquire, store and use of teaching resources and information in time.(2)Cooperation.In the process of learning, team between learners can form learning community according to the specific purpose. Learners in community discuss,share and exchange all sorts of resources in order to arouse the enthusiasm of learners and give full play to the initiative of the learners.(3)Network.E-learning must be based on the Internet, and follows the 
network technology and the web browser with single standard, so that it can format a global interconnected knowledge and information management platform.(4)Traceability.E-learning platform can realize follow-up records throughout the learning process.In the end of the study, the effect of learning can be evaluated and learning needs analysis can be made. (5)Personalization.The concept of E-learning makes individualized learning easy to become a reality.With the help of E-platform,learners can study without limitation of time and space.They can also choose their learning content according to the personal background and learning style.

\section{Analysis of current situation for employee E-learning training in Chinese enterprises The situation for application of employee E-learning training}

Research on E-learning in China lags behind foreign countries ten years nearly.At present, the vast majority of users of E-learning are limited to telecommunications, insurance,banking,IT companies and some other major enterprise.However, in United States, the development of E-learning has entered into the mature stage.E-learning produces a new form of digital learning with development,such as blog-learning, blend-learning,board-learning and beyond-learning.According to the estimate of IDC(Internet Data Center),E-learning training application is jumped at an annual rate of 83\%, will reach $40 \%$ of the total volume ${ }^{[2]}$.

There are two main types of application of employee E-learning training.First,enterprises built E-learning system all by themselves and carry out training business through internal study and management system. This way is mainly used in the large enterprise.Second,enterprises purchase or rent learning account from E-learning service provider,so that employees study online courses directly by the Internet.This approach is mainly used in small and medium enterprises.

At the same time,E-learning is becoming more and more concerned in China, and many large enterprises have set up their own E-learning training system.From the report of the use of E-learning in Chinese enterprises in 2011, it can be found that the proportion of traditional training inputs has been reduced each year, while the proportion of E-learning training inputs has been increased each year.The inputs is risen from 7.3\% in 2009 to 15.3\% in 2011.Among enterprises with E-learning platform at present, about $20 \%$ of the training is done through E-learning, and $22 \%$ of the training is done by combining E-learning and traditional training.

\section{The advantages of application of employee E-learning training}

The situation of knowledge economy requires enterprises to grasp the new opportunities and to cope with new problems in a timely manner.E-learning greatly meets the need of enterprises for internal training. The analysis of study form in enterprise is shown in Table $1^{[3]}$.

Table 1 Analysis of study form in enterprise

\begin{tabular}{|c|l|c|c|}
\hline $\begin{array}{c}\text { Non-online } \\
\text { learning }\end{array}$ & $\begin{array}{l}\text { Self-study based on the } \\
\text { traditional media }\end{array}$ & Group discussion & \multicolumn{1}{c|}{$\begin{array}{c}\text { Traditional } \\
\text { class teaching }\end{array}$} \\
\hline Online learning & $\begin{array}{l}\text { Interactive learning } \\
\text { mode based on the } \\
\text { network,eg. MOOCs }\end{array}$ & $\begin{array}{l}\text { Learning group based on } \\
\text { network;discussion } \\
\text { between group members }\end{array}$ & $\begin{array}{l}\text { Mass teaching methods } \\
\text { based on video } \\
\text { conference }\end{array}$ \\
\hline & Autonomic learning & Group learning & Collective teaching \\
\hline
\end{tabular}

There are four advantages of application of employee E-learning training.

First of all,learning based on the way of network training can be more closely combined with practical activities for employees. Online training is based on employees' responsibility so that it can promote working ability and reduce the staff training cost effectively.

Secondly,online learning is a kind of achievement sharing and is also a way of autonomous learning.Employees choose their learning methods and learning content with advantages of the options in time and space and flexibility.This can effectively reduce the time cost of face-to-face learning.

Thirdly,the enterprise as a system should accumulate personal experience and improve the skills of decision-making.Therefore, the enterprise staff training is transformed simple internal training into 
knowledge management and the construction of learning organization. While E-learning is useful to improve productivity and decreases cost.

Finally,the enterprise spreads key skills that are not only personal ability but also organizational core skills.Online learning makes this process easier and it can reduce the learning cost.

\section{The problems of application of employee E-learning training}

(1)The barrier for direct communication.From the perspective of technical development of the E-learning, interactive communication has no problem in technology, including the real-time interactive video.However, compared to face-to-face communication, it is always lack of emotional communication.

(2)The lack of targeted training curriculum and resources.The content of network curriculum is one of the important factors that affects learning outcome.Good curriculum and resources usually can stimulate the learning motivation of employees.In addition, there are some other problems in the process of enterprise E-learning training,such as inappropriate highlights of courses, lack of interest and obscure performance.

(3)Degree of motivating employees is not enough.Most companies have no good supervision and incentive system to arouse the enthusiasm of staff to use the way of E-learning to study.Due to network training replaces direct face-to-face communication of people,trainers cannot timely understand employee needs.And most of employees have to undergo a transformation of idea to accept E-learning. The lack of incentives influences learning motivation.

(4)The ability of staff in the aspect of information is low and the enterprise is short of qualified trainers.Enterprise E-learning training based on the network training requires the learners to master the ability of information technology.This ability is also the important premise for smooth implementation for E-learning training.At the same time,enterprise is also lack of excellent trainers, and then leading to poor training effect.

(5)Dependence on the construction of network infrastructure.E-learning needs the strong support of information technology, including hardware such as computers, network equipment and software such as learning management system, standard course.These reflect unique aspect of the E-learning training $^{[4]}$.

\section{Countermeasures against the problems of application of employee E-learning training}

(1)Attaching great importance to the interpersonal communication and collaboration in the process of training.Learning interest and initiative have been improved greatly when learners introduce themselves,ask questions or share learning experience with other colleagues.As a result, online training must create atmosphere of community.Employees in organization can learn how to communication,improve learning atmosphere and exchange learning experience.

(2)Establishing perfect personalized training certification system.E-learning is not only simply online learning by Internet,but is actually a kind of integrated solutions containing a set of standardized technology and management.So enterprises must adopt a set of complete training curriculum system $^{[5]}$.Employees can clearly know their own career development and free to choose courses to learn according to their goals and situations.Finally they can get the professional or other relative certification.

(3)Stimulating employee motivation and creating training incentive mechanism.Managers can use Maslow's hierarchy of needs theory and training incentive mechanism to arouse the enthusiasm of staff training.Maslow's hierarchy of needs theory states that people have the need of respect and self-actualization.Therefore,enterprise should set up dedicated training management system and make effective incentive system to arouse the enthusiasm of employees to participate in the training.Combined with promotion, salary incentive mechanism, training can stimulate the desire of self-actualization and enhance learning motivation.

(4)Training idea that human resources in the enterprise becomes first should be set up.Doing a good training demand analysis is necessary.Everyone should be aware of the importance of human resources and management in the process of operation. The enterprise training should be added in 
corporate strategic planning.Completing the training needs analysis before actions is significant.Training content,methods and staffing must comply with its own actual situation.

(5)Constructing network learning motivation.Although in Internet age the new way of learning such as E-learning is not strange for many workers,E-learning acquires a targeted promotion strategy in order to obtain good results. Through the comprehensive analysis,the network learning motivation strategy can be constructed by three dimensions of content,promotion and application(Fig.1 ${ }^{[6]}$.In this strategy,enterprises innovate network,promote learning achievements,create a good learning atmosphere and stimulate employee motivation.

(6)Ensuring the normal operation of infrastructure.As an online training program, it will give the learners direct difficulties and reduce the enthusiasm of learners, especially increase learners' resistance in the beginning of stage if there is no stability and no support of information technology.

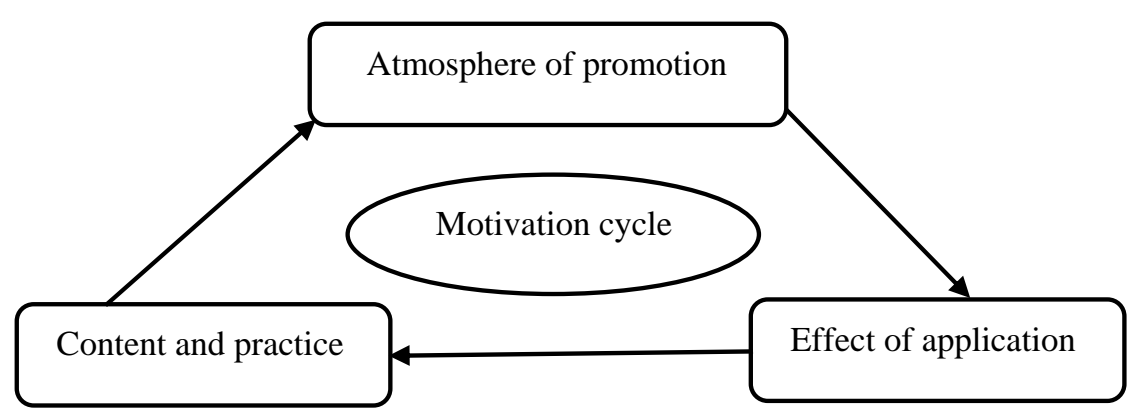

Fig. 1 Network learning motivation

Enterprise has a good base for the information, which can provides convenience for the successful implementation of online training program .

(7)Evaluation and follow-up of Training effect.E-learning has an important feature, that is to track the students' learning and format assessment.The mechanism for evaluation of study effect in the each quarter should be made.According to the feedback, and statistical analysis of student behavior based on the management technology, each student's learning effect can be comprehensively evaluated.In this way enterprise motivates enthusiasm of staff and guarantees the learning effect.

\section{Summary}

Compared with international level, domestic application of employee E-learning training still has great potential.E-learning will be inevitable trend in human resources management and human resources training in large and medium-sized enterprise.The construction of E-learning system requires a lot of time and resources.Enterprises should advance with the times, consider the social development and the characteristics of the enterprise, tailor E-learning training solution for enterprise development,and then the enterprises can be in an impregnable position under the fierce and brutal competition.

\section{References}

[1] Yuan Xin,The Research on E-learning training:Journal of Changchun University of Thchnology (social Sciences Edition),Vol.25,No.04,Jul 2013.

[2] Wang Naihan and Cao Lin,A Study on E-learning for Enterprise Training System:China Educational Technique and Equipment,Vol.15,May 2012.

[3] Wu Zhanjie,The Integrated Learning in the Age of Big Data:Path to Large-scale Personalized Learning:Journal of Open Education Research,Vol 19,No4,Aug 2013.

[4] Yan Chunyan, A Research on E-learning training:Managers’ Journal,Jan.2014.

[5] Xue Zhimei,Liu Haihua ,The Current Situation and Countermeasures of E-learning training in China:Hebei Normal University of Science Technology(Social Sciences),Vol 10 No.3,Sept 2011.

[6] Yan Dongping,Promotion and Application of E-learning in Enterprises:Joural of Contemporary Economics,Nov 2013. 